January 2017

\title{
Promoting Environments that Measure Outcomes: Partnerships for Change
}

Roseann C. Schaaf

Department of Occupational Therapy, Thomas Jefferson University

Amy P. Carroll

Department of Occupational Therapy, Thomas Jefferson University

Susan Toth-Cohen

Thomas Jefferson University

Janice P. Burke

Thomas Jefferson University

Caryn Johnson

Thomas Jefferson University

See next page for additional authors

Follow this and additional works at: https://encompass.eku.edu/jote

Part of the Occupational Therapy Commons

\section{Recommended Citation}

Schaaf, R. C., Carroll, A. P., Toth-Cohen, S., Burke, J. P., Johnson, C., \& Herge, E. (2017). Promoting Environments that Measure Outcomes: Partnerships for Change. Journal of Occupational Therapy Education, 1 (2). https://doi.org/10.26681/jote.2017.010204

This Educational Innovations is brought to you for free and open access by Encompass. It has been accepted for inclusion in Journal of Occupational Therapy Education by an authorized editor of Encompass. For more information, please contact Linda.Sizemore@eku.edu. 


\title{
Promoting Environments that Measure Outcomes: Partnerships for Change
}

\begin{abstract}
This paper describes the development of the PrEMO ${ }^{\complement}$ (Promoting Environments that Measure Outcomes) program. PrEMO ${ }^{\circledR}$ is an innovative model promoting evidence-based practice (EBP) while developing capacity and quality of Level II fieldwork placements. The PrEMO ${ }^{\complement}$ program is described from initiation to completion, including development of site-specific learning objectives, the twelve week schedule and the role of faculty mentorship. Occupational therapy (OT) students, and university OT program faculty including academic fieldwork coordinators, partner with fieldwork educators at the site to implement EBP using a datadriven decision making (DDDM) process to guide the development of evidence-based practices. PrEMO ${ }^{\complement}$ appears to be a useful strategy for building Level II fieldwork capacity and enhancing student and fieldwork educators' knowledge and skills about EBP and outcome measurement in routine OT practice.
\end{abstract}

Keywords

Fieldwork, evidence-based practice, occupational therapy education, data driven decision making, outcome measurement

\section{Creative Commons License}

\section{(c) (1) (9)}

This work is licensed under a Creative Commons Attribution-Noncommercial-No Derivative Works 4.0 License.

\section{Acknowledgements}

We wish to thank the fieldwork educators and students who participated in this project and the sites themselves for participation. In addition, we thank the entire PrEMO@ team including Tina DeAngelis, Stephen Kern, Kimberly Mollo and Lydia Navarro Walker for their efforts in developing the program.

\section{Authors}

Roseann C. Schaaf, Amy P. Carroll, Susan Toth-Cohen, Janice P. Burke, Caryn Johnson, and E. Adel Herge 


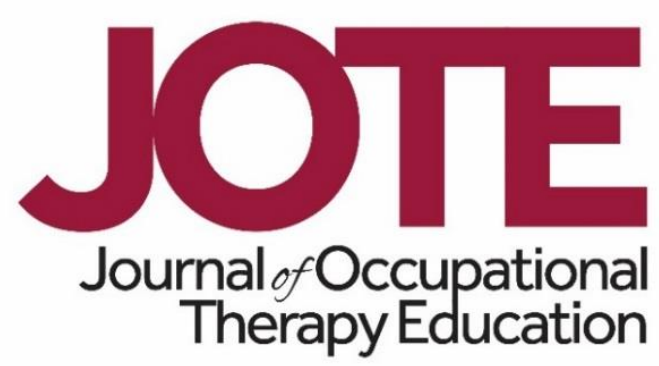

Volume 1, Issue 2

Promoting Environments that Measure Outcomes: Partnerships for Change

Roseann C. Schaaf, PhD, OTR/L, FAOTA

Amy P. Carroll, OTD, OTR/L

Susan E. Toth-Cohen, PhD, OTR/L

Janice P. Burke, PhD, OTR/L, FAOTA

Caryn Reichlin Johnson, MS, OTR/L, FAOTA

E. Adel Herge, OTD, OTR/L, FAOTA

Thomas Jefferson University

United States

\begin{abstract}
This paper describes the development of the $\operatorname{PrEMO}^{\odot}$ (Promoting Environments that Measure Outcomes) program. $\mathrm{PrEMO}^{\odot}$ is an innovative model promoting evidencebased practice (EBP) while developing capacity and quality of Level II fieldwork placements. The $\mathrm{PrEMO}^{\odot}$ program is described from initiation to completion, including development of site-specific learning objectives, the twelve week schedule and the role of faculty mentorship. Occupational therapy (OT) students, and university OT program faculty including academic fieldwork coordinators, partner with fieldwork educators at the site to implement EBP using a data-driven decision making (DDDM) process to guide the development of evidence-based practices. $\operatorname{PrEMO}^{\odot}$ appears to be a useful strategy for building Level II fieldwork capacity and enhancing student and fieldwork educators' knowledge and skills about EBP and outcome measurement in routine OT practice.
\end{abstract}

\title{
INTRODUCTION
}

The American Occupational Therapy Association's Centennial Vision (AOTA, 2007) directed the profession's collective attention toward ideals that would strengthen our position in the increasingly competitive health care landscape. Aligning with the World Health Organization's (WHO) International Classification of Functioning, Disability and Health (ICF), an international standard to describe and measure health and disability, the Centennial Vision tasked the occupational therapy community with establishing 
evidence-based, science-driven practice that meets society's occupational needs (AOTA, 2007). As a result, over the past decade the emphasis on evidence-based practice (EBP) and the use of outcome measurement in clinical practice has increased substantially and significant strides have been made with respect to increasing accessibility of evidence for use by clinicians (Burke \& Gitlin, 2012; Clark, Park, \& Burke, 2013). In addition, EBP has become an integral part of occupational therapy curricula as mandated by the Accreditation Council of Occupational Therapy Education (ACOTE, 2012). Still, studies indicate that the actual use of research evidence in every day practice remains low, with few clinicians basing clinical decisions on professional literature or published research (Salls, Dolhi, Silverman, \& Hansen, 2009). This "research to practice gap" (Squires et al., 2011) is a growing concern across health care (Castiglione \& Ritchie, 2012; Ciliska, 2012; WHO, 2006). Also described as the secondgap of knowledge translation (Woolf, 2008) and the know-do gap (WHO, 2006), the lag in application of research knowledge to practice has been identified by the director of the WHO as "one of the most important challenges facing public health in this century" (WHO, 2006, p. 1).

The AOTA Vision 2025 statement also reflects a desire to bridge the research-practice gap and emphasizes effective solutions to facilitate participation in everyday living with guideposts that explicitly include EBP and effective outcomes (AOTA, 2016). To realize Vision 2025 and demonstrate the value of occupational therapy, academic institutions must create opportunities for clinicians and students to implement EBP (DeAngelis, Demarco, \& Toth-Cohen, 2013; Schaaf, 2015). Barriers impeding the use of EBP include perceived lack of time, knowledge and skill, as well as the belief it may limit the ability to provide client-centered or family-centered care (Harding, Porter, HorneThompson, Donely, \& Taylor, 2014; Majid et al., 2011; Ubbink, Guyatt, \& Vermeulen, 2013). Recommendations for enhancing EBP include stronger links between education, research, and practice (AOTA, 2007); collaboration across stakeholder groups (including educators, clinicians, researchers, organizations, and policymakers); and strategies to include outcome measurement into routine practice (Burke \& Gitlin, 2012; Law, 2002; Lin, Murphy, \& Robinson, 2010; MacDermid, Law, \& Michlovitz, 2014; Schaaf, 2015). Moreover, greater attention to the use and creation of evidence and charting outcomes must take place within a climate that fosters achievement of the triple aims of health care which are to: 1) improve the individual experience of care, 2) improve the health of populations, and 3) reduce the cost of care (Berwick, Nolan, \& Whittington, 2008).

With the goal of promoting EBP and providing exemplary practice models for student training, our university occupational therapy program took deliberate steps to create partnerships with the clinical community and included faculty, academic fieldwork coordinators (AFWC), entry-level Master Occupational Therapy students, combined Bachelor to Master Occupational Therapy students, and fieldwork educators who would work together to promote EBP. The purpose of this paper is to describe this program and the principles that guided its development and implementation. 


\section{HISTORY OF THE PROGRAM}

Twenty years ago, this university occupational therapy educational program recognized a need for students to train in sites that utilized EBP. Simultaneously, the university extended its longstanding commitment to community partnerships by cultivating fieldwork sites in community-based settings. This served to offset the shortage of fieldwork sites and to provide innovative venues for student training (Miller \& Johnson, 2005). These early efforts paved the way for the program described in this paper, which was designed to provide opportunities to translate research knowledge into practice, and train clinicians and students in EBP. As an unexpected benefit, the partnerships grew into clinical laboratories where faculty partner with fieldwork sites to measure program outcomes, foster growth in new models for practice, and extend occupational therapy services into community agencies.

The early plan that guided program development was straight forward. As part of a course assignment, students conducted a needs assessment with assigned community agencies and presented the results to the agency stakeholders. In some cases, the needs assessment resulted in small foundation-funded grants or university-funded grants to support program development. In others, community agencies responded by providing funding to support part-time occupational therapists to serve as fieldwork educators. The objective was for each site to establish evidence-based, outcomeoriented occupational therapy programing that provided best-practice opportunities for students. In this way, the seeds of the current program were established. These early partnerships served as the template for university-fieldwork collaborations, identifying sites that offered the greatest readiness for further development which led to the current program (described below).

\section{PROGRAM DESCRIPTION}

This program, termed $\operatorname{PrEMO}^{\odot}$ (Promoting Environments that Measure Outcomes) became the catalyst for customizing and facilitating EBP in occupational therapy fieldwork sites. With $\operatorname{PrEMO}^{\odot}$, university occupational therapy faculty partner with fieldwork sites to develop and implement a comprehensive student fieldwork education program that simultaneously guides fieldwork educators in the use of evidence and outcome measurement for occupational therapy practice. $\operatorname{PrEMO}^{\odot}$ is notable in that it 1) combines didactic content on EBP and outcome measurement with direct mentorship of students and fieldwork educators during the Level II fieldwork experience, 2) uses a data driven decision making framework (DDDM) (Schaaf, 2015) to systematically build knowledge and skills, 3) transforms the student training program by integrating site specific learning objectives (SSLO) and site specific outcome measurement to create unique learning experiences designed to build knowledge and skills around evidence and outcome measurement, and 4) directly applies new knowledge to practice via an indepth, case report by each student. The mission of $\operatorname{PrEMO}^{\odot}$ is three-fold:

- To create partnerships for exemplary EBP environments for occupational therapy students. 
- To promote consistent use of best evidence and systematic outcome measurement in occupational therapy service delivery.

- To develop sustainable, innovative occupational therapy programs in traditional and non-traditional (or emerging) settings.

Best practice for occupational therapy is defined as that which is client-centered, seated in occupation, uses theory to guide practice, in corporates the use of assessment measures and assessment data into practice, uses best-evidence to guide interventions, and systematically measures outcomes of intervention (AOTA, 2014). As shown in Figure 1, $\operatorname{PrEMO}^{\odot}$ accomplishes these objectives by joining education with clinical practice and by using a systematic and data driven approach to implement best evidence in practice. $\mathrm{PrEMO}^{\odot}$ is designed to train students to become evidence-based and outcomes-oriented practitioners, facilitate the use of evidence by practitioners and support their efforts to develop and evaluate programs, and promote effective and sustainable models of service delivery within the partner organizations. Thus, $\operatorname{PrEMO}^{\odot}$ aims to build overall student, practitioner, and organizational capacity to enable best practice and promote outcomes research.

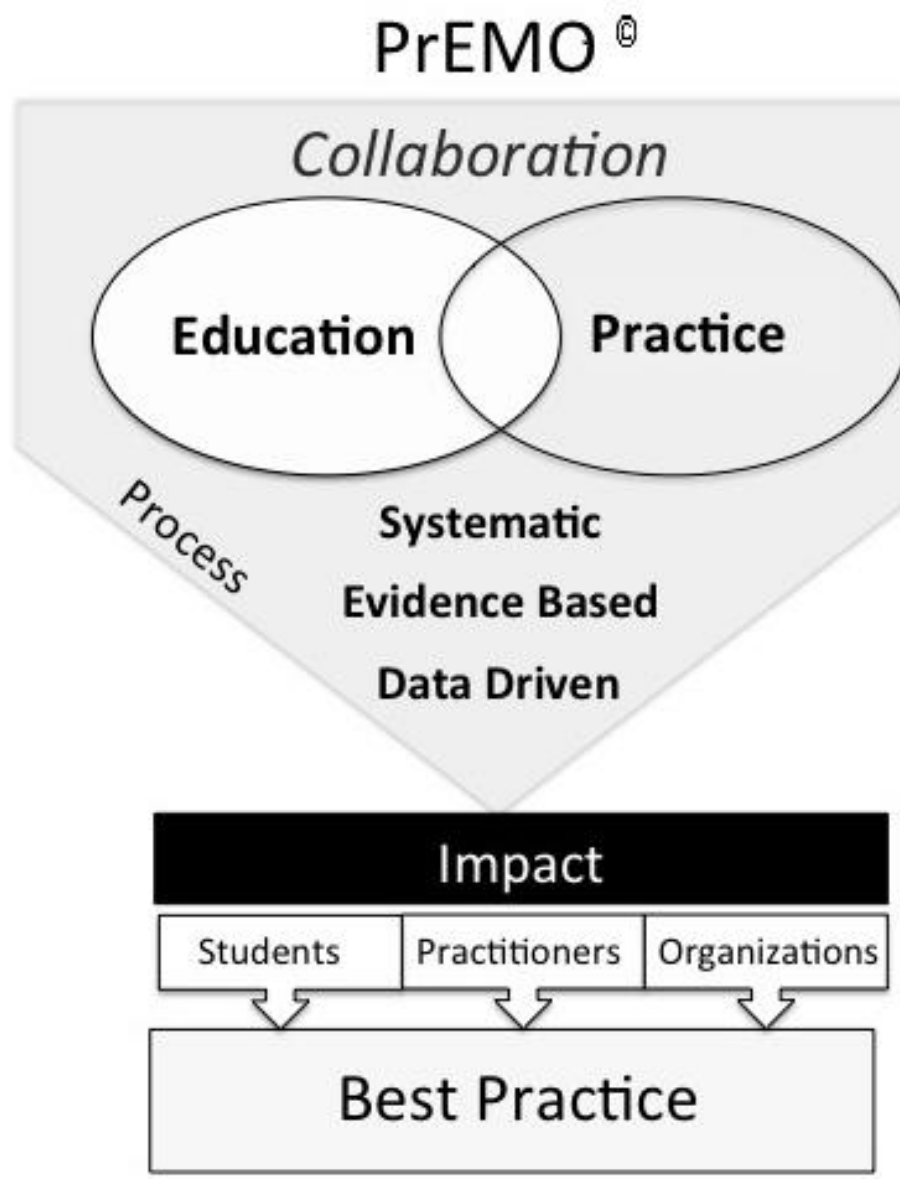

Figure 1: Conceptual overview of $\operatorname{PrEMO}^{\odot}$. 


\section{DEVELOPMENT OF A PREMO ${ }^{\odot}$ SITE}

The development of a $\operatorname{PrEMO}^{\odot}$ site consists of a thoughtful partnership between the fieldwork site, the university, and the student. To accomplish this aim, the university occupational therapy program identified the $\mathrm{PrEMO}^{\odot}$ facilitator, a faculty member who would oversee the $\mathrm{PrEMO}^{\odot}$ initiative across sites, and assigned $20 \%$ of their effort to $\mathrm{PrEMO}^{\odot}$. The $\mathrm{PrEMO}^{\odot}$ facilitator and the AFWC worked closely together to spearhead the program development effort. The activities involved in the development and implementation of $\mathrm{PrEMO}^{\odot}$ site and the roles of the facilitator and $\mathrm{AFWC}$ are described below.

\section{Identification of Clinical Sites}

The first stage of establishing $\mathrm{PrEMO}^{\odot}$ is to identify fieldwork sites that are interested in partnering with university faculty to enhance student learning and occupational therapy practice in ways that are relevant to site stakeholders (e.g. the fieldwork educators, clinicians, administrators, policymakers, and clients). For example, $\mathrm{PrEMO}^{\odot}$ may focus on integration of evidence-based practices, promotion of systematic, data driven approaches, and/or development of innovative programs. To begin, the $\operatorname{PrEMO}^{\odot}$ faculty team meets with fieldwork educators and/or administrators (especially in the case when there is not an OT on site) at the fieldwork site to discuss $\operatorname{PrEMO}^{\odot}$ and provide the $\mathrm{PrEMO}^{\odot}$ fact sheet. This fact sheet outlines the mission and goals of $\mathrm{PrEMO}^{\odot}$ as well as the responsibilities of each partner. The partnership draws on the resources of all partners including a second faculty member, the faculty site mentor, who has knowledge in the population served by the site, and the student who agrees to serve as the catalyst for the knowledge translation and implementation. The role of the faculty site mentor is described below.

Next, the $\operatorname{PrEMO}^{\odot}$ facilitator, AFWC, and the faculty site mentor meet with the site to collect information about the site's mission, goals, core values, strategic plan, populations served, current level of occupational therapy services, and the organization's overall willingness to apply time and resources to support student involvement. In addition, the site's readiness for implementation of EBP and outcome measurement is discussed. Additional areas considered include the site's experience with applying theoretical constructs and EBPs, as well as level of experience, use, and perceived value of standardized assessment and measurement of outcomes at the programmatic, systems, and client levels. Based on these data, a timeline with common goals and outcomes are identified and the partnership is initiated.

\section{The Faculty Site Mentor}

Once the partnership is initiated, a $\mathrm{PrEMO}^{\odot}$ faculty member who has expertise in the content that matches the services provided or needed at a site is identified. This individual becomes the faculty site mentor and works closely with the AFWC, the site administration, the fieldwork educators, and the $\mathrm{PrEMO}^{\odot}$ facilitator to develop the program. Faculty site mentor activities include working with the AFWC and fieldwork educator to establish the twelve-week student schedule, development of the SSLOs (described below), tailoring the DDDM process for the site, choosing the specialty 
knowledge areas that will be the focus of the fieldwork experience, and identifying potential areas for program development and/or research. During the implementation phase, the site becomes the "laboratory" for the faculty site mentor's scholarly activities including training, program development, translation of knowledge to practice, and research. An example of faculty site mentor activities are described in Appendix A: Sample of Faculty Site Mentor Activities.

\section{Training of Site Staff and Students in Data driven Decision Making} Data driven decision making (DDDM) is used to guide the site development in EBP (Schaaf, 2015). As shown in Figure 2, DDDM is a systematic process that has been applied to OT practice. It has many useful features including its ability to facilitate the identification and measurement of occupation-based outcomes. DDDM is described in detail elsewhere (Carroll, Herge, Johnson, \& Schaaf, 2017; Schaaf, 2015; Schaaf \& Mailloux, 2015). Briefly, DDDM uses a series of steps to explicate and guide the occupational therapy process. First, the client's goals are identified and the strengths and challenges of the client are assessed. This assures that the intervention is targeted to client needs and focuses on occupation and participation. Next, the theoretical perspective(s) that will guide the occupational therapy process are identified. These are based on the client's needs and goals, the setting, and support from the literature. Guided by the theoretical perspective, assessments are selected and administered. Assessment data is used to identify the factors that facilitate and hinder the identified participation challenges and hypotheses are developed to link the factors affecting performance and participation to client goals. The use of a hypothesis statement is a key feature of the DDDM approach and serves not only to link theory and assessment data, but also to clearly identify intervention targets and outcomes. Next, goals are described and articulated in a measurable way, outcome measures are identified, and a plan for outcome measurement and data collection is outlined.

Once the goals, hypotheses, and outcome measurement strategies are in place, the intervention approach, setting and dosage are selected and described in sufficient detail for implementation and replication. Students are guided to published literature, evidence-based intervention manuals, and in instances when these are not available, they are guided toward compatible and comparable literature to identify EBPs. Dosage and frequency are determined based on existing evidence and outcomes are measured, monitored, and analyzed to determine whether the intervention was effective or requires modification. 


\section{Data Driven Decision Making}

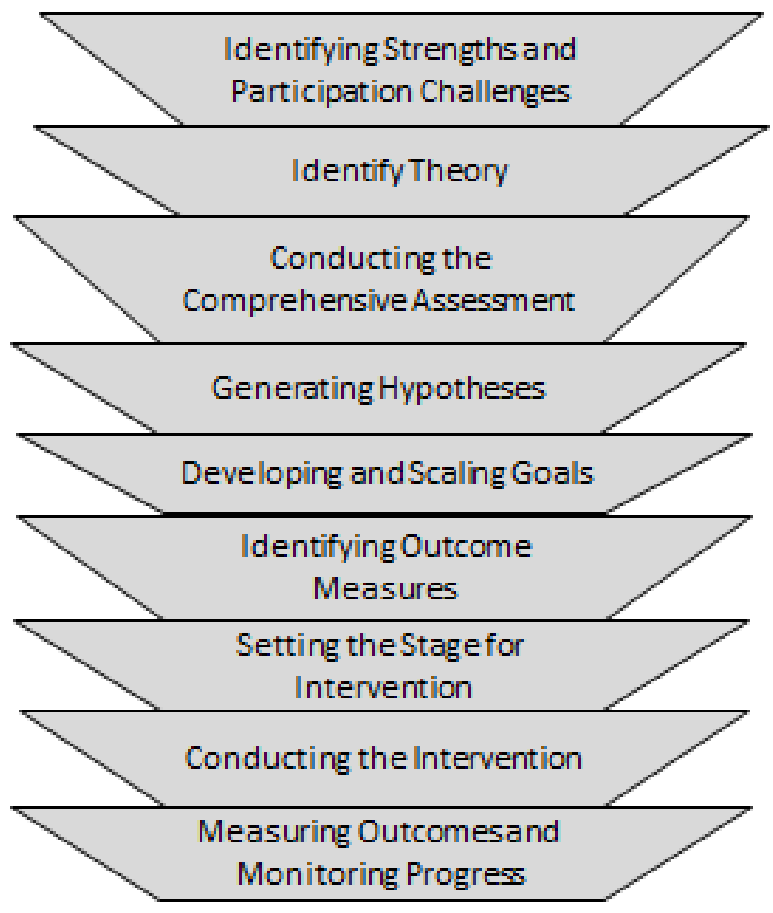

Figure 2: Data Driven Decision Making Process for Occupational Therapy (Schaaf, 2015). Used with permission from author.

As part of a case report assignment during their Level II fieldwork, students document their implementation of DDDM in detail for at least one client. A template that specifies each step of DDDM was developed for this purpose (Carroll et al., 2017). While coaching the student during this DDDM implementation, the faculty mentor learns the real world contextual factors that impact practice at the site and the fieldwork educator advances their skills for systematic, evidence-based, data-driven, outcome-oriented practice. The faculty site mentor facilitates and monitors the student and fieldwork educator's progression through the DDDM process in addition to arranging weekly meetings to evaluate progress and troubleshooting solutions for challenging situations that present themselves.

In addition to participating in learning activities related to EBP and DDDM, the fieldwork educator is invited to participate in a graduate-level advanced practice certificate program to learn more about the application of these skills.

\section{Development of the Level II Fieldwork Program Including SSLOs}

The AFWC creates the Level II fieldwork program in collaboration with the PrEMO ${ }^{\odot}$ facilitator, faculty site mentor, and the fieldwork educator at the $\mathrm{PrEMO}^{\odot}$ site. When a new $\operatorname{PrEMO}^{\odot}$ site is under development, students also provide valuable input by conducting needs assessments, identifying appropriate assessment tools, and outcome measures under the guidance of the faculty site mentor via a Level I fieldwork 
experience. The section below highlights four areas integral to the development of a fieldwork program in a $\mathrm{PrEMO}^{\odot}$ site: preparation of the fieldwork educators, development of the fieldwork manual, development of the twelve-week schedule, and identification of the SSLOs.

Preparation of fieldwork educators/ building and sustaining relationships. Fieldwork educators in $\mathrm{PrEMO}^{\odot}$ sites collaborate closely with the faculty site mentor, PrEMO $^{\odot}$ facilitator and AFWC to develop the student program. Monthly meetings begin 6-12 months before the first Level II fieldwork students arrive. This process involves a substantial time investment of approximately 3-6 hours per week over the 6-12 month planning period; however, the investment yields valuable results including a clear roadmap for student training and the evolving transformation of the site into an EBP experience. As part of the $\mathrm{PrEMO}^{\odot}$ partnership, each site commits to providing 4-8 Level II student placements per year, thus enhancing the capacity for fieldwork training.

The fieldwork manual. The $\mathrm{PrEMO}^{\odot}$ fieldwork student manual includes standard content for a fieldwork manual, such as information about the site and its policies and procedures, SSLOs, twelve-week schedule, guidelines for documentation, and schedule for supervision (Costa, 2016). In addition, the PrEMO ${ }^{\odot}$ fieldwork student manual includes important resources for EBP and DDDM, DDDM assignment information and templates, and resources related to site specific client populations and interventions. The PrEMO ${ }^{\odot}$ fieldwork student manual becomes the roadmap for student education and includes a twelve-week student training schedule with $\mathrm{PrEMO}^{\odot}$ activities included, as described below.

The twelve-week schedule. Fieldwork sites that have existing student programs superimpose the twelve-week $\mathrm{PrEMO}^{\odot}$ schedule on the existing twelve-week student training schedule, whereas sites that do not have experience with Level II occupational therapy students work with the AFWC and PrEMO ${ }^{\odot}$ facilitator to create one. The template for the twelve-week schedule is based on recommendations in the literature (Costa, 2016). It outlines the student learning activities and expectations throughout the fieldwork experience on a week-by-week basis, including progression of caseload expectations, dates and times for supervision meetings, sequence of skill development, and description, sequence and due dates of learning activities. The schedule is designed to progress students from novice to entry-level practitioner, gradually developing competency in content related to the standards for occupational therapy education and fieldwork such as learning the occupational therapy process, administration and interpretation of client specific assessment tools, goal writing, note taking, and application of specific intervention strategies consistent with the ACOTE standards (ACOTE, 2012). Simultaneously, students participate in weekly activities designed to promote knowledge acquisition and application of EPB and DDDM. An example of the twelve-week schedule is shown in Appendix B.

Site-specific learning objectives. Site-specific learning objectives (SSLO), also known as behavioral objectives, are created for the $\operatorname{PrEMO}^{\odot}$ site. These correspond to the AOTA fieldwork performance evaluation tool (FWPE; AOTA, 2002) and are 
customized to the specific fieldwork site's needs. Many of the SSLOs in the FWPE evaluation and intervention areas reference concepts included in the DDDM process. For example, SSLOs related to establishing an accurate and appropriate plan based on the evaluation results, clients' priorities, and appropriate theoretical perspective, might include skills related to steps 1-4 of the DDDM process such as identification of clients' participation challenges, identification of appropriate theoretical perspective(s), use of assessment data and interpretation of assessment data to generate hypotheses that identify factors that impact participation challenges, and the use of standardized outcome measures to evaluate progress in clients' goals.

Once the $\operatorname{PrEMO}^{\odot}$ program development tasks are completed, the Level II student program is initiated. Students are typically assigned in pairs, using a collaborative model of fieldwork education. As mentioned above, the faculty site mentor meets with the students and fieldwork educator weekly. These meetings may be in person or via electronic technology such as SKYPE (https://www.skype.com/en/). Each meeting addresses specific learning content such as the application of DDDM, crafting replicable, evidence-based, client-centered intervention plans, or the identification of appropriate outcome measures. This meeting time also serves as an opportunity for scholarly discourse, integration of knowledge, questions and answers. Student progress is monitored via weekly assignments and activities.

\section{Measuring Outcomes of PrEMO ${ }^{\odot}$}

As a means of measuring the impact of $\mathrm{PrEMO}^{\odot}$ on student and fieldwork educators' knowledge, skills, and attitudes of EBP, a pre-post quasi-experimental design study was conducted to: 1) assess the change in students' knowledge, skills and attitudes of EBP as a result of participation in $\mathrm{PrEMO}^{\odot}$ and 2) evaluate the impact of the program on fieldwork educators' knowledge, skills, and attitudes about EBP. This study is described in detail in a separate manuscript (Carroll et al., 2017). Findings showed that students had significant improvements in both their knowledge about using evidence and data in practice $(p<.05)$, and in their skills in using DDDM in practice $(p<.05)$. No significant change in attitude was noted. Students maintained a positive attitude toward DDDM pre and post study.

\section{DISCUSSION}

$\operatorname{PrEMO}^{\odot}$ offers an example of how university occupational therapy programs, with the aim of providing quality fieldwork experiences for students, can partner with fieldwork sites to promote use of evidence and outcome measurement in everyday practice. $\mathrm{PrEMO}^{\odot}$ partnerships support Vision 2025 (AOTA, 2016), bridge the education to clinic (Henderson, 2016) and the research to practice gaps in EBP that are often discussed in health care education and practice (King, Wright, \& Russell, 2011; Kitson et al., 2008; Squires et al., 2011; WHO, 2006; Woolf, 2008). In addition, $\mathrm{PrEMO}^{\odot}$ offers a strategy for quality fieldwork experiences for students, supports the unique goals of clinicians and their organizations, and creates practice-based scholarship opportunities for faculty. Through the use of DDDM which facilitates routine outcome measurement, PrEMO ${ }^{\odot}$ partnerships not only use evidence, but also "create evidence through practice" (Schaaf, 2015, p. 5). 
In this paper, we described the development and implementation of PrEMOC as a guide for other occupational therapy educational programs to consider. Many authors have described strategies to promote EBP in health profession curricula, however, most are academic exercises that include didactic coursework on EBP combined with faculty mentoring through engagement in research projects or learning activities (Aronson, Rebeschi, \& Killion, 2007; Boruff \& Thomas, 2011; Moch, Cronje, \& Branson, 2010). $\mathrm{PrEMO}^{\odot}$ is unique in that it creates an active partnership whereby educators, clinicians and students work together in the clinical setting to demonstrate EBP in action and to improve the quality of practice in ways that are relevant to the stakeholders at each site. The outcomes of $\mathrm{PrEMO}^{\odot}$ are reported by Carroll et al. (2017), and included findings that students demonstrated significant improvement in knowledge and skills in using evidence-based, data-driven principles, and that fieldwork educators valued $\operatorname{PrEMO}^{\odot}$ as an opportunity to advance their professional skills and enhance the occupational therapy services at their site (Carroll et al., 2017).

$\operatorname{PrEMO}^{\odot}$ resulted from a collaborative dialogue of university occupational therapy faculty including the AFWC, with a focused commitment to enhance occupational therapy practice. Many of the strategies utilized in $\operatorname{PrEMO}^{\odot}$ were born from these conversations and thoughtful reflections by faculty who were versed in the EBP literature. One exciting part of this process was the opportunity for faculty to draw on their clinical experience and expertise to impact practice. Faculty quickly became invested in $\operatorname{PrEMO}^{\odot}$ and created opportunities for occupational therapy practitioner-educator partnership not only for education of students, but also as opportunities for practicebased research. As a result, several faculty site mentors are now involved in scholarly inquiry projects in conjunction with $\mathrm{PrEMO}^{\odot}$ site practitioners. This was an unexpected but welcomed outcome for the clinical sites as well as the university faculty.

The investment in $\mathrm{PrEMO}^{\odot}$ by all partners resulted in mutually beneficial outcomes. The university occupational therapy program benefits by obtaining a commitment for a specific number of exemplary fieldwork experiences for their students each year. The clinical site receives training and guidance on the implementation of systematic evidence-based practices, strategies for integrating outcome measurement into daily, routine practice, and the opportunity for new program development. Faculty have active involvement in promoting EBP in traditional and emerging practice settings as well as opportunities to participate in scholarly inquiry projects at the $\mathrm{PrEMO}^{\odot}$ sites.

Fieldwork educators recognize the value $\mathrm{PrEMO}^{\odot}$ offers for furthering their own professional development as they become more skillful and systematic with EBP (Carroll et al., 2017). Fieldwork educators also find the DDDM process strengthens their communication with stakeholders about the occupational therapy process (Carroll et al., 2017). After participating in $\mathrm{PrEMO}^{\odot}$ during their Level II fieldwork, entry-level occupational therapy students demonstrated significant improvement in knowledge and skills using evidence-based, data-driven principles for occupational therapy intervention (Carroll et al., 2017). This is a win-win experience as the occupational therapy university program, the fieldwork educator, the fieldwork setting, and the occupational therapy student benefit from enhanced training, scholarship, and EBP. 
The implementation of $\mathrm{PrEMO}^{\odot}$ requires commitment of resources by the university occupational therapy program and the $\operatorname{PrEMO}^{\odot}$ facilitator is a key part of the program's success. In terms of time resources, the university occupational therapy program committed $20 \%$ of the $\operatorname{PrEMO}^{\odot}$ facilitator's time to develop, implement and monitor $\mathrm{PrEMO}^{\odot}$. The $\mathrm{PrEMO}^{\odot}$ facilitator promotes the mission, goals, and activities associated with the development and implementation of $\mathrm{PrEMO}^{\odot}$ via monthly $\mathrm{PrEMO}^{\odot}$ meetings with university occupational therapy faculty, as well as regular meetings with each $\mathrm{PrEMO}^{\odot}$ team to foster integration of key values and skill sets such as DDDM into each $\mathrm{PrEMO}^{\odot}$ site and monitor its adoption and implementation. The $\mathrm{PrEMO}^{\odot}$ facilitator also maintains a website that warehouses the various documents, templates and reading materials associated with $\operatorname{PrEMO}^{\odot}$.

Since the onset, the AFWCs have recognized the value of $\operatorname{PrEMO}^{\odot}$ as a way to increase student access to exemplary Level II fieldwork opportunities, thus investment and commitment from the AFWCs played an important role in $\operatorname{PrEMO}^{\odot}$ development and implementation. Their continued involvement in $\operatorname{PrEMO}^{\odot}$ as monitors of the Level II fieldwork student experiences is an invaluable component of $\mathrm{PrEMO}^{\odot}$.

Finally, the university occupational therapy program must also provide release time for the faculty site mentor to support their role in facilitating content-specific learning at the $\mathrm{PrEMO}^{\odot}$ site. The time commitment of the faculty site mentor varies from a few hours a week to a full day a week and is based on the site's needs, the fieldwork educator's initial level of knowledge and skill in EBP, and the site's investment in change. In community-based sites where there may not be an occupational therapist on site, the faculty site mentor serves as the fieldwork educator as well as the faculty site mentor and a $20 \%$ release time is built into the faculty member's workload to account for the one-day per week time commitment. As mentioned above, key benefits for the university occupational therapy program's investment include faculty scholarship and exemplary student training. Given that the university occupational therapy program views $\operatorname{PrEMO}^{\odot}$ as having multiple benefits for the educational program, this effort is supported by the Chair and Dean, and adequate time commitment is allocated for each faculty site mentor.

\section{Future Directions}

Every $\operatorname{PrEMO}^{\odot}$ site is unique in terms of the setting and the client population served. Discussion about these individual circumstances led the faculty to explore ways to conceptualize and measure each site's progress toward implementation of exemplary EBP and outcome measurement in daily occupational therapy practice. Moving forward, a more explicit use of implementation science to guide integration of evidence-based practices, interventions and policies into routine practice will be used (Burke \& Gitlin, 2012; Clark et al., 2013; Fogerty International Center, National Institute of Health, 2014). Further, the Promoting Action on Research Implementation in Health Sciences (PARiHS) framework has recently been integrated into $\mathrm{PrEMO}^{\odot}$ (Helfrich, Li, Sharp, \& Sales, 2009). The organization of PARiHS into three core elements of evidence, context, and facilitation, provides a useful structure for examining the key factors that 
have a role in the success of $\operatorname{PrEMO}^{\odot}$. Additionally, we plan to use the Helfrich et al. (2009) Organizational Readiness to Change Assessment (ORCA), which is based on the core elements of the PARIHS model, to evaluate each clinical site's readiness to change and to inform implementation planning. The ORCA allows partners to examine capacity at the intervention, clinician, and organizational level and provides useful data for program planning and implementation.

\section{Conclusions and Implications for Occupational Therapy}

$\mathrm{PrEMO}^{\odot}$ is an innovative program developed to address the need for EBP in occupational therapy. The program partners with sites and uses DDDM and student Level II fieldwork experiences as catalysts for training and implementation of EBP into existing and new sites. Based on data evaluating the outcomes of $\mathrm{PrEMO}^{\odot}$ (Carroll et al., 2017), $\operatorname{PrEMO}^{\odot}$ shows strong promise for accomplishing its objectives as students demonstrated improvements in their knowledge and skills related to using evidence and data in practice. As such, $\operatorname{PrEMO}^{\odot}$ provides a model for university-clinical partnership that can change and advance practice, improve patient care, and enhance student education and training. PrEMOC serves as a strategy to bridge the gap between the classroom and the practice setting, and move research to practice. Data thus far supports the positive impact of $\operatorname{PrEMO}{ }^{\odot}$-like partnerships between other university occupational therapy programs and the occupational therapy practice community and their constituents.

\section{References}

Accreditation Council for Occupational Therapy Education (ACOTE®) Standards. (2012). American Journal of Occupational Therapy, 66, S74. doi:10.5014/ajot.2012.66S6.

American Occupational Therapy Association. (2002). Fieldwork performance evaluation for the occupational therapy student. Bethesda, MD: AOTA Press.

American Occupational Therapy Association. (2007). AOTA's centennial vision and executive summary. American Journal of Occupational Therapy, 61(6), 613-614. doi:10.5014/ajot.61.6.613.

American Occupational Therapy Association. (2014). Occupational therapy practice framework: Domain and process (3rd Ed.). American Journal of Occupational Therapy, 68(Suppl. 1), S1-S48. doi:10.5014/ajot.2014.682006.

American Occupational Therapy Association. (2016). AOTA unveils Vision 2025. Retrieved from http://www.aota.org/aboutaota/vision-2025.aspx.

Aronson, B. S., Rebeschi, L. M., \& Killion, S. W. (2007). Enhancing evidence bases for interventions in a baccalaureate program. Nursing Education Perspectives, 28(5), 257-262.

Berwick, D. M., Nolan, T. W., \& Whittington, J. (2008). The triple aim: Care, health, and cost. Health Affairs (Project Hope), 27(3), 759-769. doi:10.1377/hlthaff.27.3.759.

Boruff, J. T., \& Thomas, A. (2011). Integrating evidence-based practice and information literacy skills in teaching physical and occupational therapy students. Health Information \& Libraries Journal, 28(4), 264-272. doi: 10.1111/j.14711842.2011.00953.x 
Burke, J. P., \& Gitlin, L. N. (2012). How do we change practice when we have the evidence? American Journal of Occupational Therapy, 66(5), e85-e88. doi:10.5014/ajot.2012.004432.

Carroll, A., Herge, E. A., Johnson, L., \& Schaaf, R. C. (2017). Outcomes of an evidence-based, data-driven model fieldwork experience for occupational therapy students. Journal of Occupational Therapy Education. 1(1). Retrieved from http://encompass.eku.edu/jote/vol1/iss $1 / 7$

Castiglione, S. A., \& Ritchie, J. A. (2012). Moving into action: We know what practices we want to change, now what. An implementation guide for health care practitioners. Retrieved from http://www.cihr-irsc.gc.ca/e/45669.html

Ciliska, D. (2012) Introduction to evidence-informed decision making. Retrieved from http://www.cihr-irsc.gc.ca/e/45245.html

Clark, F., Park, D. J., \& Burke, J. P. (2013). Dissemination: Bringing translational research to completion. American Journal of Occupational Therapy, 67(2), 185193. doi:10.5014/ajot.2012.004432.

Costa, D. M. (2016). The essential guide to occupational therapy fieldwork education (2nd ed.). Bethesda, MD: AOTA Press.

DeAngelis, T. M., DiMarco, T. G., \& Toth-Cohen, S. (2013). Evidence-based practice in occupational therapy curricula. Occupational Therapy in Health Care, 27(4), 323332. http://dx.doi.org/10.3109/07380577.2013.843115

Fogarty International Center, National Institutes of Health. (2014). Implementation science information and resources. Retrieved from: http://www.fic.nih.gov/researchtopics/pages/implementationscience.aspx

Harding, K. E., Porter, J., Horne-Thompson, A., Donley, E., \& Taylor, N. F. (2014). Not enough time or a low priority? Barriers to evidence-based practice for allied health clinicians. Journal of Continuing Education in the Health Professions, 34(4), 224-231. doi:10.1002/chp.21255

Helfrich, C. D., Li, Y., Sharp, N. D., \& Sales, A. E. (2009) Organizational readiness to change assessment (ORCA): Development of an instrument based on the Promoting Action on Research in Health Services (PARiHS) framework. Implementation Science, 4(38), 1-13. doi:10.1186/1748-5908-4-38

Henderson, W. (2016). Development of a clinical performance assessment tool for an occupational therapy teaching clinic. Open Journal of Occupational Therapy, 4(3). doi: 10.15453/2168-6408.1217

King, G., Wright, V., \& Russell, D. J. (2011). Understanding paediatric rehabilitation therapists' lack of use of outcome measures. Disability and Rehabilitation, 33(2526), 2662-2671. doi:10.3109/09638288.2011.582924.

Kitson, A. L., Rycroft-Malone, J., Harvey, G., McCormack, B., Seers, K., \& Titchen, A. (2008). Evaluating the successful implementation of evidence into practice using the PARiHS framework: Theoretical and practical challenges. Implementation Science, 3(1). doi:10.1186/1748-5908-3-1

Law, M. (2002). Participation in the occupations of everyday life. American Journal of Occupational Therapy, 56(6), 640-649. doi:10.5014/ajot.56.6.640 
Lin, S. H., Murphy, S. L., \& Robinson, J. C. (2010). Facilitating evidence-based practice: Process, strategies, and resources. American Journal of Occupational Therapy, 64(1), 164-171. doi:10.5014/ajot.64.1.164

MacDermid, J., Law, M., \& Michlovitz, S. (2014). Outcome measurement in evidencebased rehabilitation. In M. Law and J. Macermid (Eds.), Evidence-based rehabilitation: A guide to practice (3 ${ }^{\text {rd }}$ ed., pp. 65-104). Thorofare, New Jersey: Slack, Inc.

Majid, S., Foo, S., Luyt, B., Zhang, X., Theng, Y. L., Chang, Y. K., \& Mokhtar, I. A. (2011). Adopting evidence-based practice in clinical decision making: Nurses' perceptions, knowledge, and barriers. Journal of the Medical Library Association, 99(3), 229-236. doi: 10.3163/1536-5050.99.3.010

Miller, K. S., \& Johnson C. (2005). New doors: A community program development model. Occupational Therapy in Health Care, 19(1-2),135-143. doi: 10.1080/J003v19n01_10

Moch, S. D., Cronje, R. J., \& Branson, J. (2010). Part 1. Undergraduate nursing evidence-based practice education: Envisioning the role of students. Journal of Professional Nursing, 26(1), 5-13. doi:http://dx.doi.org.proxy1.lib.tju.edu/10.1016/j.profnurs.2009.01.015

Salls, J., Dolhi, C., Silverman, L., \& Hansen, M. (2009). The use of evidence-based practice by occupational therapists. Occupational Therapy in Health Care, 23(2), 134-145. doi:10.1080/07380570902773305

Schaaf, R. C. (2015). Creating evidence for practice using data driven decision making. American Journal of Occupational Therapy, 69(2), 6902360010p16902360010p6. doi:10.5014/ajot.2015.010561

Schaaf, R. C., \& Mailloux, Z. (2015). Clinician's guide for implementing Ayres sensory integration: Promoting participation for children with autism. Bethesda, MD: AOTA Press.

Squires, J. E., Hutchinson, A. M., Boström, A., O'Rourke, H. M., Cobban, S. J., \& Estabrooks, C. A. (2011). To what extent do nurses use research in clinical practice? A systematic review. Implementation Science, 6(1). doi: 10.1186/17485908-6-21

Ubbink, D. T., Guyatt, G. H., \& Vermeulen, H. (2013). Framework of policy recommendations for implementation of evidence-based practice: A systematic scoping review. BMJ open, 3(1). doi: 10.1136/bmjopen-2012-001881

Woolf, S. H. (2008). The meaning of translational research and why it matters. Journal of the American Medical Association, 299(2), 211-3. doi: 10.1001/jama.2007.26.

World Health Organization. (2006). Bridging the "know-do" gap meeting on knowledge translation in global health. Geneva: World Health Organization. 
Appendix A: Sample of Faculty Site Mentor activities in a residential facility for adults with developmental disabilities and intellectual impairment

A faculty member with expertise in adults with developmental and cognitive disability had interest in serving as the faculty site mentor. To develop the site and prepare it for Level II OT students, weekly meetings with the site fieldwork educators, the AFWE, and the $\operatorname{PrEMO}^{\odot}$ facilitator were held. These resulted in the development of a twelve-week student schedule built upon the AOTA Level II guidelines for student training to integrate content related to developmental disabilities, intellectual impairment, EBP and DDDM. The DDDM process was explicated to include common theories utilized with this population, assessment tools and outcome measures that may be useful, and occupational therapy intervention strategies that may be appropriate for this population. Once the student program was initiated, the faculty site mentor continued weekly meetings with the student and fieldwork educator to facilitate integration and implementation of the DDDM process.

As an example, when lack of progress in a client's identified goal of participation in daily art class was identified, the faculty site mentor guided the student and their fieldwork educator through the DDDM and shifted the focus from a rehabilitation theoretical model to a cognitive model. Assessment data showed that a cognitive impairment (i.e. inability to follow directions) was impacting the client's ability to transfer from bed to wheelchair. Using the assessment data regarding cognitive level, the approach to transfer was modified to utilize simple, one-step cuing to reduce the cognitive load and a simple picture schedule of steps was posted above the client's bed. The outcome of participation in art class was measured via weekly charting. Outcome data showed that wheelchair transfer was now successful and the client met his goal of attending art class 3 times/week. The DDDM process facilitated the shift in theoretical perspective from a biomechanical approach that focused on the client's physical impairment to one that focused on cognitive disability.

Over the next several months, the site shifted their practice to include regular assessment of the factors impacting clients' participation (as per DDDM), regular use of standardized assessments to guide practice, and measurement of outcomes as a routine part of practice. This new paradigm expanded from the residential program into their community program. The faculty site mentor then instituted a data collection system to investigate the relationship between cognitive level and safety in community mobility for these clients. The site now serves as the "research laboratory" for this faculty site mentor who conducts research, training and program development with the site personnel. 
Appendix B: Sample Twelve Week Schedule

This sample shows the concurrent, complimentary activities of Level II fieldwork and $\operatorname{PrEMO}^{\odot}$ activities during week 2 and serves as a guide for student learning and application of evidence based practice. The schedule includes columns for application of general Fieldwork Level II competency including content of the ACOTE standards B and $\mathrm{C}$, application of EBP and the DDDM process, and content related to the population of the site. The last column of the schedule is used to track the team's ideas for collaborative research at the site. The schedule is unique to each site and is created collaboratively by the $\mathrm{PrEMO}^{\odot}$ team and the fieldwork educator with explicit priority given to the fieldwork agenda and the fieldwork educator's plans.

\begin{tabular}{|c|c|c|c|}
\hline $\begin{array}{c}\text { General Fieldwork } \\
\text { Activities }\end{array}$ & $\begin{array}{c}\text { DDDM Activities and } \\
\text { Readings }\end{array}$ & Population Content & $\begin{array}{l}\text { Potential } \\
\text { Research } \\
\text { Questions* }\end{array}$ \\
\hline $\begin{array}{l}\text { Overview: } \\
\text { Screening and } \\
\text { Assessment } \\
\text { Process } \\
\text { Identify Specific } \\
\text { assessments useful } \\
\text { for this site }\end{array}$ & $\begin{array}{l}\text { Read: } \\
\text { - Schaaf, } 2015 \\
\text { - Schaaf \& Mailloux } \\
\text { (2015) } \\
\text { - Willard \& Spackman } \\
\text { (2014): Explore } \\
\text { theory chapters } \\
\text { Review instructions } \\
\text { included in the DDDM } \\
\text { template } \\
\text { Learning Activity: } \\
\text { Collaborate with } \\
\text { fieldwork educator and } \\
\text { PrEMO }{ }^{\odot} \text { team to identify } \\
\text { a client. Use DDDM } \\
\text { template to describe } \\
\text { clinical reasoning. } \\
\text { Identify client's: } \\
\text { - Participation } \\
\text { challenges } \\
\text { - Current level of } \\
\text { functioning }\end{array}$ & $\begin{array}{l}\text { Read } \\
\text { - Willard \& } \\
\text { Spackman (2014) } \\
\text { pp. 1156-1158 } \\
\text { - Yu \& Mathiowetz } \\
\text { (2014) Parts 1 \& } 2 \\
\\
\text { Activity: Identify } \\
\text { assessments that } \\
\text { may be appropriate } \\
\text { for selected client }\end{array}$ & $\begin{array}{l}\text { Investigate } \\
\text { participation- } \\
\text { based outcome } \\
\text { measures } \\
\text { relevant to this } \\
\text { population. }\end{array}$ \\
\hline
\end{tabular}




\begin{tabular}{|l|l|l|l|}
\hline $\begin{array}{l}\text { Observe FWE } \\
\text { assessment of } \\
\text { same client. }\end{array}$ & $\begin{array}{l}\bullet \text { Theoretical } \\
\text { perspective that will } \\
\text { be used }\end{array}$ \\
$\begin{array}{l}\text { Meet with FWE for } \\
\text { supervision }\end{array}$ & $\begin{array}{l}\text { Complete the first 3 } \\
\text { sections of the DDDM } \\
\text { template and submit prior } \\
\text { to discussion at PrEMO } \\
\text { meeting }\end{array}$ &
\end{tabular}

*Some schedules include a column that supports an initiative that is highly valued by the partnering organization. Examples of $\operatorname{PrEMO}^{\odot}$ initiatives include developing a sensory friendly school environment or conducting a needs assessment for future program development. 